\title{
Risk of Venous Thromboembolism Among Patients with Atopic Dermatitis: A Cohort Study in a US Administrative Claims Database
}

\author{
Kristin J. Meyers · Jonathan I. Silverberg • Maria Jose Rueda • \\ Robert Goodloe · Evangeline J. Pierce • Walter Deberdt • \\ Dennis R. Brinker
}

Received: March 19, 2021 / Accepted: April 19, 2021 / Published online: April 30, 2021

(C) The Author(s) 2021

\section{ABSTRACT}

Introduction: Atopic dermatitis (AD) is associated with risk factors for venous thromboembolism (VTE). However, the risk of VTE among this population is unknown. The aim of this study was to assess the risk of VTE among adults with $\mathrm{AD}$ and compare the risk vs. matched nonAD controls.

Methods: This retrospective study used claims data from the IBM Watson MarketScan ${ }^{\circledR}$ Commercial Claims and Encounters, Medicare Supplemental, and Medicaid databases to identify adults aged 18 years or older with AD. Incidence rates (IR) per 100 person-years (PY) of VTE were reported for three cohorts: overall $\mathrm{AD}$, moderate-to-severe $\mathrm{AD}$, and non-AD controls matched by age, sex, and calendar time to the overall cohort. Cox proportional hazards regression

Supplementary Information The online version contains supplementary material available at https:// doi.org/10.1007/s13555-021-00538-4.

K. J. Meyers $(\bowtie) \cdot$ M. J. Rueda · R. Goodloe .

E. J. Pierce · D. R. Brinker

Lilly Corporate Center, Eli Lilly and Company,

Indianapolis, IN 46285, USA

e-mail: meyers_kristin_joy@lilly.com

J. I. Silverberg

George Washington University, Washington, DC, USA

W. Deberdt

Eli Lilly Benelux NV, Brussels, Belgium was used to estimate hazard ratios (HR) for VTE risk.

Results: Overall, 198,685 patients with AD were identified. Crude VTE IRs were 0.24 for AD overall, 0.31 for moderate-to-severe $\mathrm{AD}$, and 0.25 for non-AD controls. VTE risk was similar in patients with $\mathrm{AD}$ vs. non-AD controls (partially adjusted HR 1.00, 95\% confidence interval [CI] 0.92, 1.09). VTE risk was greater in patients with moderate-to-severe AD vs. non-AD controls in partially adjusted models (HR 1.24, 95\% CI 1.13, 1.36), but not after adjustment for healthcare use and VTE risk factors (HR 0.95, 95\% CI 0.85, 1.07).

Conclusions: AD was not an independent risk factor for VTE, and the risk of VTE among patients with $\mathrm{AD}$ was low. These findings provide valuable context for understanding VTE risk among patients with $\mathrm{AD}$, which is particularly relevant as advanced therapies for the treatment of moderate to severe $\mathrm{AD}$, such as janus kinase inhibitors, become available.

Keywords: Atopic dermatitis; Risk factors; Venous thromboembolism 


\section{Key Summary Points}

Why carry out the study?

Patients with moderate-to-severe atopic dermatitis $(\mathrm{AD})$ have a higher prevalence of factors that may increase risk for venous thromboembolism (VTE), yet the risk of VTE among this population is unknown

New therapeutic options in development for patients with moderate-to-severe AD carry a potential risk for VTE

Findings from this study can provide valuable context for understanding VTE risk among patients with $\mathrm{AD}$

What was learned from the study?

This study is the first to provide estimates of VTE incidence rates and comparative risk among a broad population of patients with $\mathrm{AD}$

This study found that AD was not an independent risk factor for VTE, and the risk of VTE among patients with AD was low

\section{DIGITAL FEATURES}

This article is published with digital features, including a summary slide, to facilitate understanding of the article. To view digital features for this article go to https://doi.org/10.6084/ m9.figshare.14431472.

\section{INTRODUCTION}

Atopic dermatitis (AD) is a chronic inflammatory skin disease that can cause considerable morbidity and impair patients' quality of life. $[1,2] \mathrm{AD}$ affects about $5.3-7.3 \%$ of adults in the
USA $[3,4]$ and is associated with a sedentary lifestyle, obesity, smoking, increased hospitalization, and the use of systemic corticosteroids [5-9]. These factors have all been shown to increase the risk of venous thromboembolism (VTE) [10-13] - a condition that is serious and potentially fatal [13].

The annual incidence of VTE, a disease which comprises deep vein thrombosis (DVT) and pulmonary embolism (PE), is estimated to be $0.1-0.2 \%$ among the general population $[12,13]$. Risk factors for developing VTE include older age ( $>45$ years), major surgery, hospitalization, comorbid conditions (e.g., cancer, inflammatory diseases, trauma, and obesity), and medication use (e.g., hormone therapy) [12-14]. Therapies being developed for the treatment of $\mathrm{AD}$, such as janus kinase inhibitors [15-17], also have a potential risk of thromboembolic events [18].

Despite the co-occurrence of VTE risk factors in patients with $\mathrm{AD}$, the risk of VTE among this population is unknown. Understanding VTE risk in patients with $\mathrm{AD}$ is important to quantify the association between these conditions. The aim of this study was to assess the risk of VTE among adults with $\mathrm{AD}$ and compare the risk with matched non-AD controls.

\section{METHODS}

\section{Study Design and Data Source}

This retrospective cohort study was conducted using data from the IBM Watson MarketScan ${ }^{\circledR}$ Commercial Claims and Encounters, Medicare Supplemental, and Medicaid databases. These databases contain inpatient and outpatient claims, outpatient prescription claims, and plan enrollment information for $>200$ million US commercial health, Medicare, and Medicaid plan enrollees. All patient data were de-identified and compliant with the Health Insurance Portability and Accountability Act of 1996; therefore, informed consent, as well as institutional or ethical review board approval, was not required. 


\section{Study Population}

Three cohorts were evaluated to assess the risk of VTE: an overall AD cohort, a sub-cohort with moderate-to-severe $\mathrm{AD}$, and a comparator cohort of non-AD controls that was 1:1 matched on 5-year age category, sex, and calendar time to the overall AD cohort. Moderate-tosevere $\mathrm{AD}$ was identified using prescription dispensing as a proxy measure, including highor ultra-high potency topical corticosteroids, systemic corticosteroids, systemic immunosuppressants, phototherapies, or biologics used at any time after $\mathrm{AD}$ diagnosis (including index date) (Table S1).

The index date was defined as the date of the first qualifying $\mathrm{AD}$ diagnosis for the overall $\mathrm{AD}$ cohort and the first date of qualifying treatment after AD diagnosis for the sub-cohort with moderate-to-severe AD (Table S1). For non-AD controls, the index date was assigned as the date of any diagnosis other than $\mathrm{AD}$ that was matched within a 1-month calendar window to a patient in the overall $\mathrm{AD}$ cohort (i.e., a diagnosis code occurring either 2 weeks before or 2 weeks after the date of a qualifying AD code in the overall $\mathrm{AD}$ cohort).

Adults aged 18 years or older on the index date and enrolled in the MarketScan databases between January 1, 2012, and October 31, 2017, were included in the study. Patients in the AD cohort were identified by the first of at least one inpatient or outpatient AD diagnosis made by a dermatologist [International Classification of Diseases, Ninth Revision, Clinical Modification (ICD-9-CM) 691.8 or 10th Revision (ICD-10CM) L20.0, L20.8x, L20.9]. All patients were required to be enrolled for at least 365 days before the index date (baseline period) and maintain continuous enrollment after the index date until the first of the following events: VTE, disenrollment from health plan, or end of the study on October 31, 2018 (follow-up period). Person-years (PY) at risk was defined as the summation of time between index (inclusive) until the first of these events. A 1-month enrollment gap was permitted during the baseline and follow-up periods.

Patients with a history of VTE at any time in all available look-back data and patients who received anticoagulation therapy (apixaban, dabigatran, dalteparin, edoxaban, enoxaparin, fondaparinux, rivaroxaban, tinzaparin, or warfarin) during the baseline period were excluded from the study. Adults in the non-AD comparator cohort who had an AD diagnosis at any time were also excluded.

\section{Outcome Measures}

\section{Characteristics of the AD Cohort}

Characteristics of patients with AD were assessed during the baseline period and included: demographics (age on index date, sex, geographic region, index year, and insurance type), measures of healthcare utilization (total healthcare costs, number of outpatient visits, and total days hospitalized), use of medication with a known or suspected increased risk for VTE (hormone therapy, methotrexate, statins, antipsychotics, cyclooxygenase-2 inhibitors, and systemic corticosteroids), and comorbidities with a known or suspected increased risk for VTE (cancer, trauma, psoriasis, rheumatoid arthritis, systemic lupus erythematosus, ulcerative colitis, Crohn's disease, and obesity). Medication use for the treatment of AD (Table S1) was assessed in the follow-up period.

\section{Risk of VTE}

VTE was defined as PE, DVT, or other venous thromboses, and this definition was informed by a US validation study for VTE identification in claims databases (Table S2). [18] The algorithm considered the setting of diagnosis (hospital vs. outpatient), position of hospital-based codes (primary or secondary position), and whether an anticoagulant was prescribed within 31 days of VTE diagnosis.

\section{Statistical Analysis}

Feasibility assessments conducted before the start of the study suggested 150,000 patients with $\mathrm{AD}$ would be identified for study inclusion. Based on this sample size, a hazard ratio (HR) for VTE of at least 1.3 could be detected with 95\% power assuming (1) a background VTE incidence rate (IR) of 0.2 per $100 \mathrm{PY}$ in the non-AD 
controls, (2) 1:1 matching, (3) average follow-up of 1 year, and (4) one-sided significance of 0.025 .

Descriptive statistics were used to characterize the study population (counts, percentage, mean, and standard deviation). IRs were calculated as the total number of incident VTE events divided by the total PY of risk in each respective cohort. IRs per $100 \mathrm{PY}$ at risk with Poisson 95\% confidence intervals (CIs) were reported and presented by the risk of VTE (overall), PE, and DVT for each cohort. If a patient experienced multiple VTE events on the same day, the patient was counted only once for VTE and up to one count for each of the individual components.

Cox proportional hazards regression models were used to estimate partially and fully adjusted HRs as a measure of the association between the risk of VTE in the overall AD cohort and sub-cohort with moderate-to-severe $\mathrm{AD}$ compared to non-AD controls. In the partially adjusted models, only the matching variables were included in the Cox model (5-year age category, sex, and calendar year). In the fully adjusted model, the Cox model was additionally adjusted for variables that were imbalanced across the cohorts $(P<0.05)$ and for risk factors of VTE including baseline healthcare utilization (number of outpatient visits, total healthcare costs, and number of days hospitalized), medication use (hormone therapy, methotrexate, statins, antipsychotics, cyclooxygenase- 2 inhibitors, and systemic corticosteroids), and comorbidities (cancer, trauma, psoriasis, rheumatoid arthritis, systemic lupus erythematosus, ulcerative colitis, Crohn's disease, and obesity). Missing data were treated as missing, and no imputation was conducted.

\section{RESULTS}

\section{Patient Population}

A total of 555,156 patients were diagnosed with AD by a dermatologist between 2012 and 2017 (Fig. 1). The overall AD cohort was composed of 198,699 patients who met the inclusion criteria; $113,927(57.3 \%)$ of them had moderate-to- severe disease based on their prescription claims for medications after initial diagnosis. For the non-AD control cohort, a pool of 23.6 million individuals qualified for matching to the overall AD cohort. A total of 198,685 patients were included in the overall $\mathrm{AD}$ and non-AD cohorts after 1:1 matching on five-year age category, sex, and calendar time.

\section{Patient Characteristics}

Characteristics of the overall AD cohort (after matching), sub-cohort with moderate-to-severe $\mathrm{AD}$, and non-AD controls (before and after matching) are presented in Table 1. After matching, the average age of patients in the overall $\mathrm{AD}$ and non- $\mathrm{AD}$ cohorts was 46 years and $65 \%$ were female. Regional distribution of patients in the $\mathrm{AD}$ and non-AD cohorts was generally similar; however, patients with $\mathrm{AD}$ were more often from the Northeast $(26.8 \%$ vs. $14.9 \%)$. A greater proportion of the AD patient population was commercially insured $(86.5 \%$ vs. $78.8 \%$ ) and had higher utilization of healthcare resources as indicated by a greater average number of outpatient visits (15.9 vs. 1.6 ) and healthcare costs ( $\$ 8727$ vs. $\$ 976$ ) in the baseline period compared to non-AD controls. The proportion of patients with prescription claims for medications with a known or suspected increased risk of VTE and with comorbidities was higher in patients with $\mathrm{AD}$, which was consistent with an overall increased use of healthcare resources.

\section{IRs of VTE}

Total PY of follow-up were 465,697 for the overall AD cohort, 261,881 for the sub-cohort with moderate-to-severe $\mathrm{AD}$, and 422,710 for the non-AD cohort. Average patient follow-up ranged from 2.1 to 2.3 years.

Crude IRs for VTE were 0.24 per 100 PY (95\% CI $0.23,0.25$ ) for $\mathrm{AD}$ overall, 0.31 per $100 \mathrm{PY}$ (95\% CI $0.29,0.34)$ for moderate-to-severe $\mathrm{AD}$, and 0.25 per $100 \mathrm{PY}(95 \% \mathrm{CI} 0.23,0.26)$ for nonAD controls (Fig. 2). Crude IRs for PE were 0.07 per $100 \mathrm{PY}(95 \%$ CI $0.07,0.08)$ for $\mathrm{AD}$ overall, 0.10 per 100 PY $(95 \%$ CI $0.09,0.11)$ for 


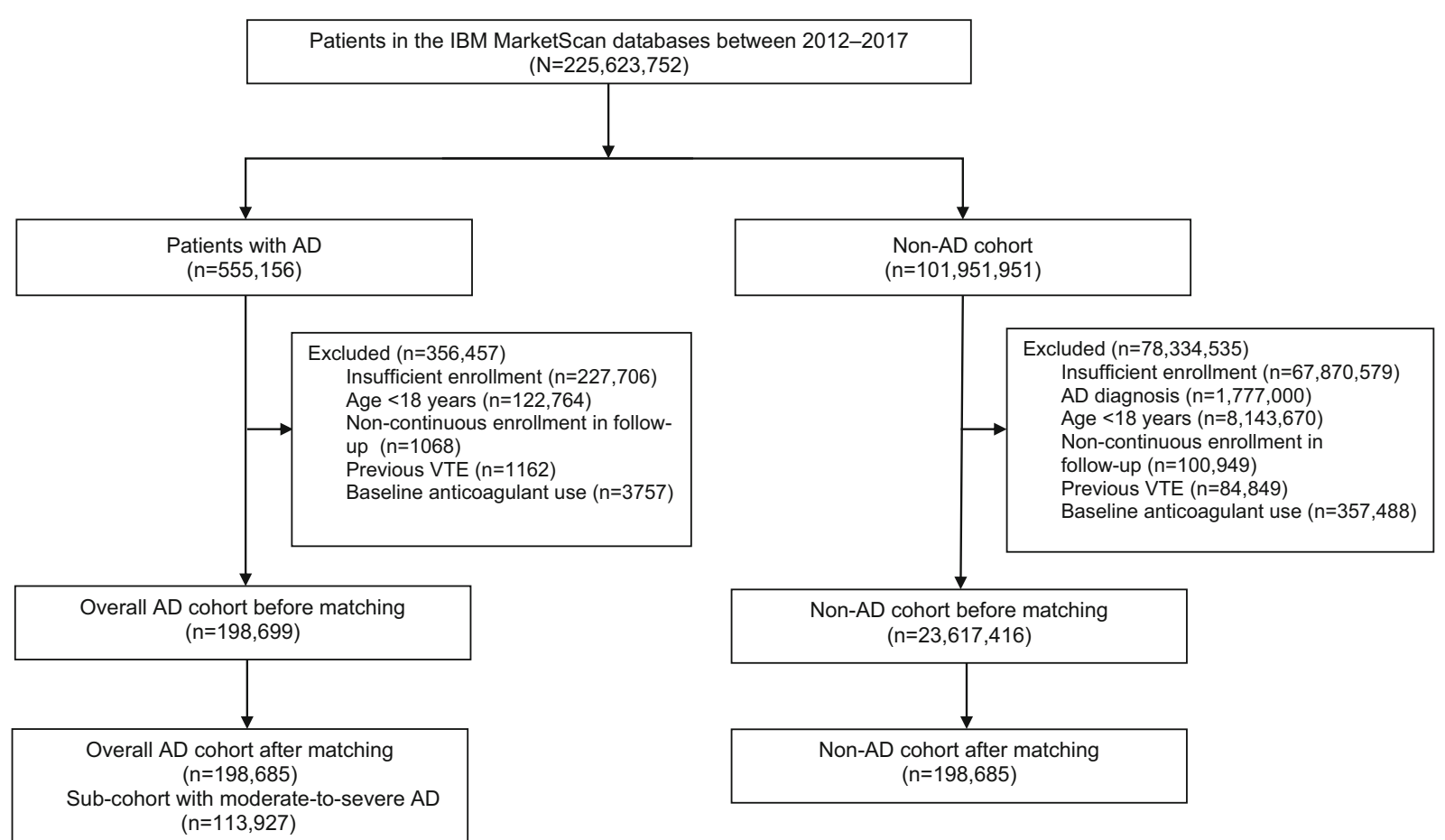

Fig. 1 Patient disposition of the AD cohorts and non-AD cohort in the IBM MarketScan databases between 2012 and 2017. $A D$ atopic dermatitis, $V T E$ venous thromboembolism

moderate-to-severe $\mathrm{AD}$, and 0.09 per $100 \mathrm{PY}$ $(95 \%$ CI $0.08,0.10)$ for non-AD controls. Crude IRs for DVT were 0.19 per 100 PY (95\% CI 0.18, $0.20)$ for $\mathrm{AD}$ overall, 0.25 per $100 \mathrm{PY}(95 \% \mathrm{CI}$ $0.23,0.27$ ) for moderate-to-severe $\mathrm{AD}$, and 0.19 per 100 PY $(95 \%$ CI $0.17,0.20)$ for non-AD controls. DVT accounted for approximately three-quarters of VTE events. No cases of other venous thrombotic events were identified.

\section{Comparative Analysis for Risk of VTE}

The risk of VTE did not differ between patients with $\mathrm{AD}$ and non-AD controls when adjusting only for the matching variables (HR 1.00, 95\% CI $0.92,1.09, P=0.95$ ) (Table 2). A decreased risk of VTE among patients with AD compared to the non-AD controls was observed after further adjusting for healthcare use and VTE risk factors (HR 0.77, 95\% CI, 0.69, 0.85, $P<0.001$ ). The risk of PE was 13-34\% lower for patients with $\mathrm{AD}$ vs. the non-AD controls (partially adjusted HR 0.87, 95\% CI 0.75, 1.01, $P=0.07$; fully adjusted HR 0.66, 95\% CI 0.56, 0.79, $P<0.001)$. The risk of DVT did not differ between patients with $\mathrm{AD}$ compared to non-AD controls when adjusting only for matching variables, but the risk decreased after adjusting for healthcare use and VTE risk factors (HR 1.04, 95\% CI $0.95,1.15, P=0.40$; fully adjusted HR $0.81,95 \%$ CI 0.72, 0.91, $P<0.001$ ).

Patients with moderate-to-severe AD had a $24 \%$ greater risk of VTE than the non-AD controls (partially adjusted HR 1.24, 95\% CI 1.13, 1.36, $P<0.001)$. However, no difference was found in risk after adjusting for healthcare use and VTE risk factors (fully adjusted HR 0.95, 95\% CI $0.85,1.07, P=0.41)$. Similar findings were observed for the risk of $\mathrm{PE}$ (partially adjusted HR 1.11, 95\% CI 0.95, 1.30, $P=0.19$; fully adjusted HR 0.83, 95\% CI 0.69, 1.01, $P=0.07$ ) and DVT (partially adjusted HR 1.28, 95\% CI 1.16, 1.42, $P<0.001$; fully adjusted HR $1.00,95 \%$ CI $0.88,1.14, P=0.99$ ) among patients with moderate-to-severe $\mathrm{AD}$ compared to the non-AD controls. 
Table 1 Characteristics of patients in the overall AD cohort, sub-cohort with moderate-to-severe AD, and non-AD cohort

\begin{tabular}{|c|c|c|c|c|}
\hline Characteristic & $\begin{array}{l}\text { Non-AD controls } \\
(n=23,617,416)\end{array}$ & $\begin{array}{l}\text { Non-AD controls }(\text { after } \\
\text { matching) }(n=198,685)\end{array}$ & $\begin{array}{l}\text { Overall AD } \\
(n=198,685)\end{array}$ & $\begin{array}{l}\text { Moderate-to-severe } \\
\mathrm{AD}(n=113,927)\end{array}$ \\
\hline $\begin{array}{l}\text { Age on index date, } \\
\text { mean }(\mathrm{SD})\end{array}$ & $45.6(16.2)$ & $46.1(17.1)$ & $46.0(17.0)$ & $48.0(16.7)$ \\
\hline \multicolumn{5}{|l|}{ Sex, $n(\%)$} \\
\hline Female & $12,659,337(53.6 \%)$ & $129,440(65.2 \%)$ & $129,440(65.2 \%)$ & $74,210(65.1 \%)$ \\
\hline \multicolumn{5}{|l|}{ Region, $n$ (\%) } \\
\hline Northeast & $4,284,270(18.1 \%)$ & $29,644(14.9 \%)$ & $53,152(26.8 \%)$ & $30,187(26.5 \%)$ \\
\hline North Central & $5,133,993(21.7 \%)$ & $40,184(20.2 \%)$ & $32,141(16.2 \%)$ & $18,835(16.5 \%)$ \\
\hline South & $8,718,597$ (36.9\%) & $70,439(35.5 \%)$ & $76,071(38.3 \%)$ & $45,114(39.6 \%)$ \\
\hline West & $4,085,996(17.3 \%)$ & $36,802(18.5 \%)$ & $32,150(16.2 \%)$ & $17,035(15.0 \%)$ \\
\hline Unknown & $317,519(1.3 \%)$ & $2176(1.1 \%)$ & $2128(1.1 \%)$ & $1051(0.9 \%)$ \\
\hline \multicolumn{5}{|l|}{ Index year, $n(\%)$} \\
\hline 2012 & $20,244,245(85.7 \%)$ & $56,134(28.3 \%)$ & $56,134(28.3 \%)$ & $24,221(21.3 \%)$ \\
\hline 2013 & $1,428,351(6.1 \%)$ & $38,365(19.3 \%)$ & $38,365(19.3 \%)$ & $21,460(18.8 \%)$ \\
\hline 2014 & $741,951(3.1 \%)$ & $36,060(18.2)$ & $36,060(18.2 \%)$ & $21,740(19.1 \%)$ \\
\hline 2015 & $460,596(2.0 \%)$ & $28,429(14.3 \%)$ & $28,429(14.3 \%)$ & $17,919(15.7 \%)$ \\
\hline 2016 & $416,466(1.8 \%)$ & $22,609(11.4 \%)$ & $22,609(11.4 \%)$ & $16,446(14.4 \%)$ \\
\hline 2017 & $325,807(1.4 \%)$ & $17,088(8.6 \%)$ & $17,088(8.6 \%)$ & $12,141(10.7 \%)$ \\
\hline \multicolumn{5}{|l|}{ Insurance type, $n(\%)$} \\
\hline Commercial claims & $20,099,256(85.1 \%)$ & $156,586(78.8 \%)$ & $171,776(86.5 \%)$ & 96,437 (84.7\%) \\
\hline $\begin{array}{l}\text { Medicare } \\
\text { supplement }\end{array}$ & $2,441,119(10.3 \%)$ & $22,659(11.4 \%)$ & $23,866(12.0 \%)$ & $15,785(13.9 \%)$ \\
\hline Medicaid & $1,077,041(4.6 \%)$ & $19,440(9.8 \%)$ & $3043(1.5 \%)$ & $1705(1.5 \%)$ \\
\hline $\begin{array}{l}\text { Total healthcare costs, } \\
\text { mean }(\mathrm{SD}) \$^{\mathrm{a}}\end{array}$ & $\$ 5,041(\$ 17,783)$ & $\$ 976(\$ 6,623)$ & $\$ 8,727(\$ 24,467)$ & $\$ 10,469(\$ 26,675)$ \\
\hline $\begin{array}{l}\text { Total outpatient } \\
\text { visits, mean }(\mathrm{SD})\end{array}$ & $9.4(23.4)$ & $1.6(9.3)$ & $15.9(23.4)$ & $18.3(25.1)$ \\
\hline $\begin{array}{l}\text { Total days } \\
\text { hospitalized, mean } \\
\text { (SD) }\end{array}$ & $0.3(2.6)$ & $0.1(0.9)$ & $0.3(2.4)$ & $0.4(2.5)$ \\
\hline \multicolumn{5}{|c|}{ Use of $\mathrm{AD}$ medications, $n(\%)$} \\
\hline $\begin{array}{l}\text { Systemic } \\
\text { corticosteroid }\end{array}$ & $7,531,386(31.9 \%)$ & $44,170(22.2 \%)$ & $90,646(45.6 \%)$ & $84,939(74.6 \%)$ \\
\hline $\begin{array}{l}\text { Biologic } \\
\text { (dupilumab) }\end{array}$ & $99(0)$ & $1(0)$ & $1202(0.6 \%)$ & $1108(1.0 \%)$ \\
\hline
\end{tabular}


Table 1 continued

\begin{tabular}{|c|c|c|c|c|}
\hline Characteristic & $\begin{array}{l}\text { Non-AD controls } \\
(n=23,617,416)\end{array}$ & $\begin{array}{l}\text { Non-AD controls (after } \\
\text { matching) }(n=198,685)\end{array}$ & $\begin{array}{l}\text { Overall AD } \\
(n=198,685)\end{array}$ & $\begin{array}{l}\text { Moderate-to-severe } \\
\text { AD }(n=113,927)\end{array}$ \\
\hline $\begin{array}{l}\text { Systemic } \\
\text { immunosuppressant }\end{array}$ & $240,093(1.0 \%)$ & $843(0.4 \%)$ & $5040(2.5 \%)$ & $4916(4.3 \%)$ \\
\hline Phototherapies & $28,852(0.1 \%)$ & $113(<0.1 \%)$ & $4701(2.4 \%)$ & $4641(4.1 \%)$ \\
\hline $\begin{array}{l}\text { High- or ultra-high } \\
\text { potency topical }\end{array}$ & $1,620,625(6.9 \%)$ & $7458(3.8 \%)$ & $66,686(33.6 \%)$ & $63,559(55.8 \%)$ \\
\hline \multicolumn{5}{|c|}{ Baseline use of medications with possible VTE risk, $n$ (\%) } \\
\hline Hormone therapy ${ }^{\mathrm{b}}$ & $2,363,642(10.0 \%)$ & $10,568(5.3 \%)$ & $32,931(16.6 \%)$ & $18,687(16.4 \%)$ \\
\hline Methotrexate & $99,322(0.4 \%)$ & $195(0.1 \%)$ & $1469(0.7 \%)$ & $1270(1.1 \%)$ \\
\hline Statins & $3,892,022(16.5 \%)$ & $12,507(6.3 \%)$ & $35,063(17.7 \%)$ & $23,136(20.3 \%)$ \\
\hline Antipsychotics & $451,101(1.9 \%)$ & $1076(0.5 \%)$ & $3847(1.9 \%)$ & $2451(2.2 \%)$ \\
\hline COX-2 inhibitors & $247,032(1.1 \%)$ & $632(0.3 \%)$ & $2822(1.4 \%)$ & $2042(1.8 \%)$ \\
\hline $\begin{array}{l}\text { Systemic } \\
\text { corticosteroids }\end{array}$ & $3,052,957$ (12.9\%) & $7813(3.9 \%)$ & $59,271(29.8 \%)$ & $33,564(29.5 \%)$ \\
\hline \multicolumn{5}{|l|}{ Comorbidities, $n$ (\%) } \\
\hline Cancer & $988,242(4.2 \%)$ & $1534(0.8 \%)$ & $12,133(6.1 \%)$ & $7590(6.7 \%)$ \\
\hline Trauma & $142,054(0.6 \%)$ & $172(0.1 \%)$ & $2195(1.1 \%)$ & $1535(1.4 \%)$ \\
\hline Psoriasis & $131,183(0.6 \%)$ & $200(0.1 \%)$ & $4677(2.4 \%)$ & $3681(3.2 \%)$ \\
\hline Rheumatoid arthritis & $170,817(0.7 \%)$ & $220(0.1 \%)$ & $2062(1.0 \%)$ & $1629(1.4 \%)$ \\
\hline $\begin{array}{l}\text { Systemic lupus } \\
\text { erythematosus }\end{array}$ & $31,169(0.1 \%)$ & $39(<0.1 \%)$ & $450(0.2 \%)$ & $361(0.3 \%)$ \\
\hline Ulcerative colitis & $66,762(0.3 \%)$ & $102(<0.1 \%)$ & $961(0.5 \%)$ & $661(0.6 \%)$ \\
\hline Crohn disease & $61,534(0.3 \%)$ & $108(<0.1 \%)$ & $913(0.5 \%)$ & $636(0.6 \%)$ \\
\hline Obesity & $745,915(3.2 \%)$ & $1174(0.6 \%)$ & $13,161(6.6 \%)$ & $8876(7.8 \%)$ \\
\hline
\end{tabular}

Patient characteristics were assessed during the 1-year baseline period, except for the medications used for the treatment of atopic dermatitis, which were assessed in the follow-up period. The medications considered in each subcategory are outlined in Table $S 1$

$A D$ atopic dermatitis, $C O X-2$ cyclooxygenase-2, $S D$ standard deviation, $V T E$ venous thromboembolism

${ }^{a}$ Reported costs are not disease specific

b Hormone therapy includes oral contraceptives 


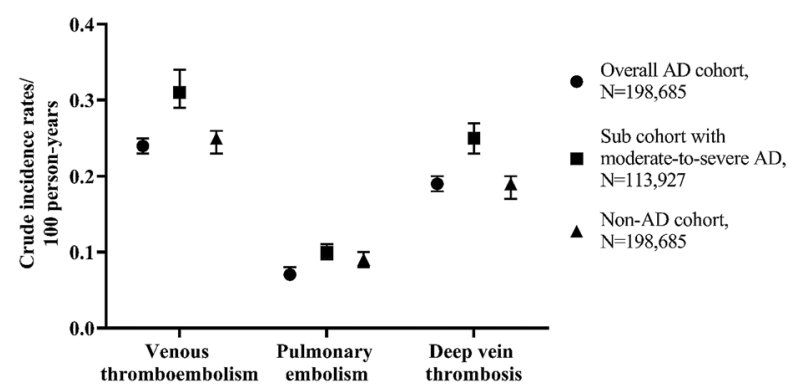

Fig. 2 Crude IRs (per 100 PY) of VTE, including DVT and $\mathrm{PE}$, in the $\mathrm{AD}$ and non-AD cohorts. IRs are presented per 100 PY. The numbers of VTE events were 1112 (PE 345, DVT 884) in the overall AD cohort, 823 (PE 263, DVT 648) in the sub-cohort with moderate-to-severe AD, and 1036 (PE 366, DVT 790) in the non-AD cohort. No cases of other venous thrombotic events were identified. $A D$ atopic dermatitis, $P Y$ patient-years, VTE venous thromboembolism

\section{DISCUSSION}

The results of this retrospective cohort study suggested that $\mathrm{AD}$ is not an independent risk factor for VTE, and the risk of VTE among patients with AD is low. The IRs of VTE among patients with $\mathrm{AD}(0.24$ per $100 \mathrm{PY})$ and the non-
AD controls matched by age, sex, and calendar time $(0.25$ per $100 \mathrm{PY})$ were nearly identical. After adjusting for multiple indicators of healthcare use, diagnoses, and medications which may increase the risk of VTE, the HR for VTE among patients with AD compared to nonAD controls was 0.77. This finding was not unexpected given that the distribution of baseline risk factors for VTE was higher in the overall $\mathrm{AD}$ cohort compared to the non-AD cohort, yet the IRs were similar between cohorts. Therefore, this indicates that the relative risk of VTE is lower for those with vs. without $\mathrm{AD}$ conditional on having the same measured risk factors.

A slightly higher IR of VTE (0.31 per 100 PY) was observed for the cohort with moderate-tosevere $\mathrm{AD}$. These patients were older, had a higher prevalence of comorbidities, and had greater medication use at baseline compared to other patients with $\mathrm{AD}$ or the non-AD controls. The moderate-to-severe $\mathrm{AD}$ cohort had a greater risk of VTE than the non-AD cohort (partially adjusted HR 1.24); however, no difference in VTE risk was observed between cohorts (fully adjusted HR 0.95) after adjusting for VTE risk factors. Similar findings were observed for the

Table 2 Partially and fully adjusted HRs for risk of VTE in AD cohorts compared to a matched non-AD cohort

\begin{tabular}{|c|c|c|c|c|c|}
\hline & \multirow[t]{2}{*}{ No. of events } & \multicolumn{2}{|c|}{ Partially adjusted $H^{a}$} & \multicolumn{2}{|c|}{ Fully adjusted $H^{b}$} \\
\hline & & HR (95\% CI) & $P$ & HR (95\% CI) & $P$ \\
\hline \multicolumn{6}{|c|}{ Overall $\mathrm{AD}$ cohort vs. non $\mathrm{AD}$ cohort } \\
\hline VTE & 2148 & $1.00(0.92,1.09)$ & 0.95 & $0.77(0.69,0.85)$ & $<0.001$ \\
\hline $\mathrm{PE}$ & 711 & $0.87(0.75,1.01)$ & 0.07 & $0.66(0.56,0.79)$ & $<0.001$ \\
\hline DVT & 1674 & $1.04(0.95,1.15)$ & 0.40 & $0.81(0.72,0.91)$ & $<0.001$ \\
\hline \multicolumn{6}{|c|}{ Sub-cohort with moderate-to-severe $\mathrm{AD}$ vs. non-AD cohort } \\
\hline VTE & 1859 & $1.24(1.13,1.36)$ & $<0.001$ & $0.95(0.85,1.07)$ & 0.41 \\
\hline $\mathrm{PE}$ & 629 & $1.11(0.95,1.30)$ & 0.19 & $0.83(0.69,1.01)$ & 0.07 \\
\hline DVT & 1438 & $1.28(1.16,1.42)$ & $<0.001$ & $1.00(0.88,1.14)$ & 0.99 \\
\hline
\end{tabular}

$A D$ atopic dermatitis, $C I$ confidence interval, $H R$ hazard ratio

a Adjusted for matching variables (5-year age category, sex, and calendar year)

b Adjusted for 5-year age category, sex, calendar year, healthcare utilization, medications (hormone therapy, systemic corticosteroid, methotrexate, statins, antipsychotics, and cyclooxygenase- 2 inhibitors), and comorbidities (cancer, trauma, psoriasis, rheumatoid arthritis, systemic lupus erythematosus, ulcerative colitis, Crohn's disease, and obesity) 
risk of PE and DVT among the three cohorts. DVTs accounted for approximately three-quarters of VTE events, consistent with what is known about VTE [19-21].

A recent cross-sectional study from the Nationwide Inpatient Sample dataset, a representative sample of US hospitalizations, described greater odds of VTE among hospitalized adults with $\mathrm{AD}$ compared to hospitalized adults without $\mathrm{AD}$ (odds ratio 1.22, 95\% CI 1.17, 1.27). [22] However, this dataset was limited to single inpatient stays; did not provide a comprehensive, longitudinal patient health record or prescription history; and could not be generalized to a non-hospitalized cohort. The present study provides the first look at estimates of VTE IRs and comparative risk among a broad population of patients with $\mathrm{AD}$, including those with moderate-to-severe disease. Furthermore, the cohort study design and the use of the IBM MarketScan databases allowed for more detailed consideration of baseline characteristics. Our analysis suggested that among patients with moderate-to-severe AD, the risk of VTE was not increased outside of any risk that would be associated with comorbidities and medications that increase the risk for VTE.

Several limitations of this study should be considered when evaluating the results. The heterogeneity of disease severity from mild $\mathrm{AD}$ to moderate or severe $\mathrm{AD}$ in the overall $\mathrm{AD}$ cohort may have introduced a "healthy user" bias. When considering the overall $\mathrm{AD}$ cohort and adjusting for measured VTE risk factors, AD was associated with a reduced risk of VTE (fully adjusted HR 0.77). However, when restricting the analysis to patients with moderate-to-severe $\mathrm{AD}$, the reduced risk of $\mathrm{AD}$ was not observed (fully adjusted HR 0.95). This suggested that the $43 \%$ of patients within the overall $\mathrm{AD}$ cohort with milder $\mathrm{AD}$ may have better general health (outside of less severe $\mathrm{AD}$ ) than those with moderate-to-severe $\mathrm{AD}$ and therefore had a lower VTE risk. The analysis was limited to patients with moderate-to-severe disease and thus addressed this potential bias by reducing misclassification of AD.

Patients with AD were identified based on inpatient or outpatient ICD-9 and ICD-10 diagnosis codes for $\mathrm{AD}$ as determined by a dermatologist. However, a previous study has found that the use of ICD-9 codes to identify patients with $\mathrm{AD}$ from healthcare databases may not be reliable [23]. This may partially explain the heterogeneous $\mathrm{AD}$ population observed in this study and the possible misclassification of $\mathrm{AD}$ to those with mild disease. Furthermore, patients with moderate-to-severe $\mathrm{AD}$ were identified based on the use of medications per US treatment guidelines [24], but the positive predictive value of this definition of $\mathrm{AD}$ has not been estimated.

No validated algorithms for defining VTE specifically within an $\mathrm{AD}$ cohort have been published to date. In this study, we applied an algorithm from a large validation study of VTE [19]. The primary analysis for the non-AD control population resulted in an IR that was within expectations of a general population from previous studies $(0.24$ per $100 \mathrm{PY}$ in this study and 0.1-0.2 per $100 \mathrm{PY}$ in published literature $[12,13])$. Despite applying the most robust algorithm available, the study by Fang and colleagues [19] did not include ICD-10 codes, was not specific to an AD population, and did not evaluate the algorithm in the MarketScan data source. The performance of the algorithm for the current study is not known and should be considered with caution given the large range of performance metrics reported on VTE algorithms from other studies [25-28].

This study did not differentiate between a prevalent or incident $\mathrm{AD}$ cohort. $\mathrm{AD}$ is a chronic inflammatory skin disease that most often starts in infancy or childhood; however, $\mathrm{AD}$ is also prevalent among adults due to either persistent childhood disease or adult onset. The life-course nature of this disease complicates the ability to identify incident vs. prevalent cases from administrative claims.

Finally, the outcomes of this study were based on US administrative claims data. Therefore, the generalizability of the risk of VTE identified in this study was limited to a subset of the US population. 


\section{CONCLUSIONS}

In conclusion, this study found that $\mathrm{AD}$ was not an independent risk factor for VTE, and the risk of VTE among patients with AD was low. The increased risk of VTE among patients with moderate-to-severe $\mathrm{AD}$ can be explained in part by comorbidities and medications that were included in this analysis and are risk factors for VTE. These findings can provide valuable context for understanding VTE risk among patients with $\mathrm{AD}$, which is particularly relevant as advanced therapies for the treatment of moderate to severe $\mathrm{AD}$, such as janus kinase inhibitors, become available.

\section{ACKNOWLEDGEMENTS}

Funding. This study and the journal's Rapid Service Fee was funded by Eli Lilly and Company and Incyte Corporation.

Medical writing, editorial, and other assistance. Medical writing was provided by Julia Zolotarjova, MSc, MWC, and editorial support by Colleen Dumont, BS, of Evidera/PPD and funded by Eli Lilly and Company (Indianapolis, IN, USA).

Authorship. All named authors meet the International Committee of Medical Journal Editors (ICMJE) criteria for authorship for this article, take responsibility for the integrity of the work as a whole, and have given their approval for this version to be published.

Authorship contributions. KJM, DRB, MJR, EJP contributed to the conceptualization and design of the study. RG performed or supported the statistical analysis. All authors contributed to the data interpretation, critically reviewed the manuscript, and approved the submitted version.

Prior presentation. Results reported in this manuscript were presented as an original poster at the European Academy of Dermatology and Venereology 2020 conference.
Disclosures. Kristin J Meyers, Maria J Rueda, Robert Goodloe, Evangeline Pierce, Walter Deberdt, and Dennis R Brinker are employees and stockholders of Eli Lilly and Company. Jonathan I Silverberg served as a consultant and/or advisory board member for AbbVie, Arena, Asana, Bluefin, Boehringer Ingelheim, Dermavant, Dermira, Eli Lilly and Company, Galderma, GlaxoSmithKline, Glenmark, Kiniksa, Leo, Novartis, Pfizer, Regeneron, Sanofi, receiving honoraria; served as a speaker for Regeneron-Sanofi; received research grants from Galderma.

Compliance with ethics guidelines. All patient data were de-identified and compliant with the Health Insurance Portability and Accountability Act of 1996; therefore, informed consent or institutional review board approval was not required.

Data availability. The datasets generated during and/or analyzed during the current study are available from the corresponding author on reasonable request.

Open Access. This article is licensed under a Creative Commons Attribution-NonCommercial 4.0 International License, which permits any non-commercial use, sharing, adaptation, distribution and reproduction in any medium or format, as long as you give appropriate credit to the original author(s) and the source, provide a link to the Creative Commons licence, and indicate if changes were made. The images or other third party material in this article are included in the article's Creative Commons licence, unless indicated otherwise in a credit line to the material. If material is not included in the article's Creative Commons licence and your intended use is not permitted by statutory regulation or exceeds the permitted use, you will need to obtain permission directly from the copyright holder. To view a copy of this licence, visit http://creativecommons.org/licenses/by$\mathrm{nc} / 4.0 /$. 


\section{REFERENCES}

1. Silverberg JI. Public health burden and epidemiology of atopic dermatitis. Dermatol Clin. 2017;35(3): 283-9. https://doi.org/10.1016/j.det.2017.02.002.

2. Birdi G, Cooke R, Knibb RC. Impact of atopic dermatitis on quality of life in adults: a systematic review and meta-analysis. Int $\mathrm{J}$ Dermatol. 2020;59(4):e75-91. https://doi.org/10.1111/ijd. 14763.

3. Chiesa Fuxench ZC, Block JK, Boguniewicz M, et al. Atopic dermatitis in America study: a cross-sectional study examining the prevalence and disease burden of atopic dermatitis in the US adult population. J Invest Dermatol. 2019;139(3):583-90. https://doi.org/10.1016/j.jid.2018.08.028.

4. Institute for Health Metrics and Evaluation (IHME). GBD Compare Data Visualization. Seattle, WA: IHME, University of Washington, 2020. http:// vizhub.healthdata.org/gbd-compare. Accessed 5 Apr 2021.

5. Zhang A, Silverberg JI. Association of atopic dermatitis with being overweight and obese: a systematic review and metaanalysis. J Am Acad Dermatol. 2015;72(4):606-16.e4. https://doi.org/10. 1016/j.jaad.2014.12.013.

6. Kantor R, Kim A, Thyssen JP, et al. Association of atopic dermatitis with smoking: a systematic review and meta-analysis. J Am Acad Dermatol. 2016;75(6):1119-25.e1. https://doi.org/10.1016/j. jaad.2016.07.017.

7. Silverberg JI, Greenland P. Eczema and cardiovascular risk factors in 2 US adult population studies. J Allergy Clin Immunol. 2015;135(3):721-8.e6. https://doi.org/10.1016/j.jaci.2014.11.023.

8. Narla S, Hsu DY, Thyssen JP, et al. Inpatient financial burden of atopic dermatitis in the United States. J Invest Dermatol. 2017;137(7):1461-7. https://doi.org/10.1016/j.jid.2017.02.975.

9. Yu SH, Drucker AM, Lebwohl M, et al. A systematic review of the safety and efficacy of systemic corticosteroids in atopic dermatitis. J Am Acad Dermatol. 2018;78(4):733-40.e11. https://doi.org/10. 1016/j.jaad.2017.09.074.

10. Waljee AK, Rogers MAM, Lin P, et al. Short term use of oral corticosteroids and related harms among adults in the United States: population based cohort study. BMJ. 2017;357:j1415. https://doi.org/ 10.1136/bmj.j1415.

11. Zhang G, Xu X, Su W, et al. Smoking and risk of venous thromboembolism: a systematic review.
Southeast Asian J Trop Med Public Health. 2014;45(3):736-45.

12. Heit JA. Epidemiology of venous thromboembolism. Nat Rev Cardiol. 2015;12(8):464-74. https://doi.org/10.1038/nrcardio.2015.83.

13. Patel K, Fasanya A, Yadam S, et al. Pathogenesis and epidemiology of venous thromboembolic disease. Crit Care Nurs Q. 2017;40(3):191-200. https://doi. org/10.1097/cnq.0000000000000158.

14. Ogdie A, Kay McGill N, Shin DB, et al. Risk of venous thromboembolism in patients with psoriatic arthritis, psoriasis and rheumatoid arthritis: a general population-based cohort study. Eur Heart J. 2018;39(39):3608-14. https://doi.org/10.1093/ eurheartj/ehx145.

15. Olumiant ${ }^{\circledR}$ (baricitinib) tablets, for oral use [US prescribing information]. 2018. https://www. accessdata.fda.gov/drugsatfda_docs/label/2018/ 207924s000lbl.pdf. Accessed 27 Oct 2020.

16. Xeljanz ${ }^{\circledR}$ (tofacitinib) tablets, for oral use [US prescribing information]. 2018. https://www. accessdata.fda.gov/drugsatfda_docs/label/2018/ 203214s018lbl.pdf. Accessed 27 Oct 2020.

17. Rinvoq ${ }^{\circledR}$ (upadacitinib) extended-release tablets, for oral use [US prescribing information]. 2019. https:// www.accessdata.fda.gov/drugsatfda_docs/label/ 2019/211675s000lbl.pdf. Accessed 27 Oct 2020.

18. Scott IC, Hider SL, Scott DL. Thromboembolism with janus kinase (JAK) inhibitors for rheumatoid arthritis: how real is the risk? Drug Saf. 2018;41(7): 645-53. https://doi.org/10.1007/s40264-018-06515 .

19. Fang MC, Fan D, Sung SH, et al. Validity of using inpatient and outpatient administrative codes to identify acute venous thromboembolism: the CVRN VTE study. Med Care. 2017;55(12):e137-43. https://doi.org/10.1097/mlr.0000000000000524.

20. Mehta KD, Siddappa Malleshappa SK, Patel S, et al. Trends of inpatient venous thromboembolism in United States before and after the surgeon general's call to action. Am J Cardiol. 2019;124(6):960-5. https://doi.org/10.1016/j.amjcard.2019.06.015.

21. Cushman M. Epidemiology and risk factors for venous thrombosis. Semin Hematol. 2007;44(2): 62-9. https://doi.org/10.1053/j.seminhematol. 2007.02.004.

22. Shaheen MS, Silverberg JI. Association of inflammatory skin diseases with venous thromboembolism in US adults. Arch Dermatol Res. 2020. https://doi.org/10.1007/s00403-020-02099-6. 
23. Hsu DY, Dalal P, Sable KA, et al. Validation of International Classification of Disease Ninth Revision codes for atopic dermatitis. Allergy. 2017;72(7):1091-5. https://doi.org/10.1111/all. 13113.

24. Eichenfield LF, Tom WL, Berger TG, et al. Guidelines of care for the management of atopic dermatitis: section 2. Management and treatment of atopic dermatitis with topical therapies. J Am Acad Dermatol. 2014;71(1):116-32. https://doi.org/10.1016/ j.jaad.2014.03.023.

25. Tamariz L, Harkins T, Nair V. A systematic review of validated methods for identifying venous thromboembolism using administrative and claims data. Pharmacoepidemiol Drug Saf. 2012;21(Suppl 1): 154-62. https://doi.org/10.1002/pds.2341.
26. White RH, Garcia M, Sadeghi B, et al. Evaluation of the predictive value of ICD-9-CM coded administrative data for venous thromboembolism in the United States. Thromb Res. 2010;126(1):61-7. https://doi.org/10.1016/j.thromres.2010.03.009.

27. Lau BD, Haut ER, Hobson DB, et al. ICD-9 codebased venous thromboembolism performance targets fail to measure up. Am J Med Qual. 2016;31(5): 448-53. https://doi.org/10.1177/1062860615583 547.

28. Ohman L, Johansson M, Jansson JH, et al. Positive predictive value and misclassification of diagnosis of pulmonary embolism and deep vein thrombosis in Swedish patient registries. Clin Epidemiol. 2018;10:1215-21. https://doi.org/10.2147/clep. S177058. 